\title{
Adherence to WHO breastfeeding guidelines among HIV positive mothers in Southern Ethiopia: implication for intervention
}

This article was published in the following Dove Press journal:

Pediatric Health, Medicine and Therapeutics

12 June 2015

Number of times this article has been viewed

\author{
Demewoz Haile' \\ Tesfaye Setegn ${ }^{2}$ \\ Sibhatu Biadgilign ${ }^{3}$ \\ 'Department of Public Health, \\ College of Medicine and Health \\ Sciences, Madawalabu University, \\ Bale Goba, Ethiopia; ${ }^{2}$ Department of \\ Reproductive Health, School of Public \\ Health, College of Medicine and \\ Health Sciences, Bahir Dar University, \\ Bahir Dar, Ethiopia; ${ }^{3}$ Independent \\ Public Health Research Consultants, \\ Addis Ababa, Ethiopia
}

Background: Breastfeeding reduces major causes of infant mortality and morbidity. On the other hand, it is a major mode of vertical HIV transmission. In developing countries like Ethiopia, HIV positive mothers are advised to continue breastfeeding up to 12 months. But there is scarce literature regarding the mothers' adherence to continued breastfeeding recommendations. Therefore, the objective of this study is to assess HIV positive mothers' adherence to the infant feeding recommendations of the new World Health Organization (WHO) guidelines for HIVexposed infants aged $\geq 6$ months.

Methods: A cross-sectional study was conducted in health institutions with antiretroviral therapy and prevention of mother to child transmission facilities in Sidama Zone, Southern Ethiopia Health institutions were considered as clusters and cluster sampling technique was employed. A total of 184 HIV positive mothers with their infants registered at respective health institutions were recruited and assessed for their infant breastfeeding practices. Descriptive statistics (frequency, mean, median, and standard deviation) were computed to describe the breastfeeding practices of HIV positive mothers.

Result: Almost all (181 [98.4\%]) of the HIV-exposed infants were "ever breastfed". Among those mothers who had ever breastfed, 158 (87.3\%) initiated breastfeeding within an hour of delivery and $157(85.8 \%)$ had fed their babies colostrum while 31 (16.8\%) gave prelacteal food to their infants. The prevalence of continued breastfeeding at 1 year was $(54.5 \%)$ ( $46.9 \%$ for urban mothers and $75 \%$ for rural mothers). Seventy-one percent (70.9\%) of HIV positive mothers practiced "on demand" breastfeeding. Twenty nine percent of infants aged 6-11 months and $47.8 \%$ of infants aged $\geq 12$ months were no longer breastfed. The mean ( \pm standard deviation) duration of breastfeeding was $7.8( \pm 3.1)$ months $(95 \%$ confidence interval: 6.9-8.7).

Conclusion: The 2010 WHO guidelines and recommendations on breastfeeding duration for HIV positive mothers was not adhered to after 6 months of age. Promotion and counseling of optimal breastfeeding practice for HIV positive mothers based on the updated WHO guideline is an appropriate intervention. However, further research is recommended to evaluate the acceptance of the new 2010 WHO guideline by the health professionals and HIV positive mothers.

Keywords: HIV-exposed, infants, breastfeeding, initiation

\section{Background}

Breast milk remains the best and safest source of nutrition for the vast majority of infants. But in the era of HIV infection, breastfeeding recommendations to HIV positive mothers have changed because of the vertical transmission of the virus through breastfeeding. HIV transmission through breastfeeding could be responsible for over a third of all HIV infections among children. Even if breastfeeding is a major mode
Department of Reproductive Heagn School of Public Health, College of Medicine and Health Sciences, Bahir Dar University, PO Box 79, Bahir Dar, Ethiopia Tel +25 I 917063992

Email tesfayesetegn@yahoo.com 
of vertical HIV transmission, it reduces infant mortality from other causes, such as malnutrition and diarrheal diseases. ${ }^{1-3}$

The 2001 and 2006 WHO recommendations and guidelines on infant feeding and HIV emphasized combined promotion of exclusive breastfeeding with early cessation of breastfeeding to reduce mother to child transmission of the virus. ${ }^{4,5}$ However, studies among HIV-exposed infants in low income settings have documented that increased morbidity and mortality is associated with earlier cessation of breastfeeding compared to continued breastfeeding. ${ }^{6-8}$

Since the implementation of the 2006 WHO guideline, there were evidences suggesting that giving antiretroviral therapy (ART) to either the HIV-infected mother or HIVexposed infant can significantly reduce the risk of transmitting HIV through breastfeeding. ${ }^{9,10}$ This had recalled the reconsideration of the previous infant feeding guidelines in the context of HIV. In 2010, the new WHO guidelines entitled "Guidelines on HIV and infant feeding principles and recommendations for infant feeding in the context of HIV and a summary of evidence" was produced. ${ }^{11}$ Regarding the HIV-exposed infant feeding recommendations, the new 2010 WHO guidelines have differed from its earlier versions. According to the latest guidelines (WHO, 2010) for known HIV positive mothers, whenever antiretroviral drugs are available, exclusive breastfeeding for the first 6 months, followed by timely introduction of appropriate complementary foods and continued breastfeeding for the first 12 months are recommended. ${ }^{11}$

In Sub-Saharan Africa, the roll-out of both highly active ART and more limited prenatal ART, as well as improved understanding of risk factors for HIV transmission through breastfeeding have dramatically reduced the number of infants becoming HIV-infected. ${ }^{12}$ One of the major changes in the WHO 2010 guidelines is the recommended duration of breastfeeding. HIV positive mothers are now encouraged to breastfeed their HIV-exposed infants for a minimum of 12 months. ${ }^{11}$ The Ethiopian national prevention of mother to child transmission (PMTCT) guideline also recommends exclusive breastfeeding for the first 6 months and continued breastfeeding for at least the first 12 months. ${ }^{13}$ However, there are limited documents regarding the adherence of HIV positive mothers to the recommendations of breastfeeding practices after the implementation of the new 2010 WHO infant feeding guideline. Therefore, this study aimed to assess HIV positive mothers' adherence to the infant feeding recommendations of the new WHO guidelines for HIV-exposed infants aged $\geq 6$ months.

\section{Methods}

\section{Study setting and sample}

A facility based cross-sectional study was conducted in ten randomly selected ART and PMTCT providing government health institutions (three hospitals and seven health centers) in Sidama Zone, Southern Ethiopia. In Sidama Zone, including Hawassa town, there were 18 health institutions which were providing ART and PMTCT services. Four health institutions were excluded because they had no eligible study subjects during the study time. The remaining eligible 14 health institutions were considered as clusters. From the eligible 14 health institutions, ten health institutions (clusters) were selected randomly. All HIV-exposed infants aged $\geq 6$ months found in randomly selected health institutions were recruited.

\section{Measurements}

The items to measure adherence were developed from the WHO 2010 and national infant feeding recommendations. Timely initiation of breastfeeding (measured by time at which the baby was put to the breast) and current breastfeeding status (measured by a 24-hour breastfeeding practice) were measured based on the WHO and the national infant and young child feeding (IYCF) recommendations. ${ }^{14}$ Colostrum feeding practice was assessed by asking the mother what she did with the first milk (colostrum), while prelacteal feeding was assessed by asking the mother what she gave the child to eat or drink in the first 3 days after delivery other than breast milk. To estimate the timely initiation of breastfeeding, the ratio of infants put to the breast within 1 hour of delivery to the total number of infants was used. Breastfeeding status was assessed by asking the mother whether she had breastfed her infant in the last 24 hours. If the mother stopped breastfeeding she was asked to recall when she had stopped breastfeeding in completed months. Mothers were asked to recall frequency of breastfeeding for the previous 24 hours separately for night and day times. Continued breastfeeding practices at 1 year were defined as proportion of breastfed children aged 12-15 months. ${ }^{14}$ Adherence to the WHO, 2010 breastfeeding recommendations was measured using proportions for both recommended and non-recommended behaviors.

\section{Statistical analysis}

Data were checked for completeness and consistency, and entered, cleaned, and coded using SPSS for Windows version 20.0. Descriptive statistics (frequency, mean, median, and standard deviation [SD]) were computed for all continuous and categorical variables. 


\section{Ethical consideration}

Ethical approval was received from Hawassa University Institutional Review Board. An official letter of cooperation was also obtained from Sidama Zonal Health Department. The purpose of the study, potential risks and benefits of participating in the study were explained and written consent was secured in participants' own language. The information and collected data were kept confidential.

\section{Results}

\section{Characteristics of the respondents}

A total of 184 HIV positive mothers with HIV-exposed infants aged 6-17 months were included in the study. The mean $( \pm \mathrm{SD})$ age of mothers was $28.85( \pm 5.4)$ years. A total of $114(61.9 \%)$ HIV positive mothers had infants aged 6-12 months. One hundred and one $(54.9 \%)$ of the respondents were Protestant by religion and 77 (43.0\%) were illiterate (Table 1). One-hundred and fifty-four $(83.7 \%)$ of HIV positive mothers received information about child feeding recommendations from health professionals while about one third of them $62(33.7 \%)$ received information from television. Sixty-seven percent (67.2\%) of HIV positive mothers were receiving ART treatment and $32.8 \%$ were on ART prophylaxis.

Almost all (181 [98.4\%]) of the HIV-exposed infants had ever breastfed in their lifetime. One hundred and fifty-eight $(87.3 \%)$ breastfeeding mothers had initiated breastfeeding within 1 hour. Although 157 (85.8\%) HIV positive mothers had fed their infants colostrum, 31 (16.8\%) of them gave prelacteal food to their infants. In this study, 33 (28.9\%) of 6-11 month old infants were not currently being breastfed. Similarly, 33 (47.8\%) of infants aged $\geq 12$ months were not being breastfed currently out of whom 22 (66.7\%) had stopped being breastfed before celebrating their first birthday (Table 2).

Among those infants who were not being breastfed currently the mean $( \pm$ SD) duration of breastfeeding was 7.8 ( \pm 3.1$)$ months (95\% confidence interval 6.9-8.7). The prevalence of continued breastfeeding at 1 year was $(54.5 \%)$ with urban to rural variation ( $46.9 \%$ versus $75 \%$ ). However, the urban to rural difference in continued breastfeeding was not statistically significant $(P=0.38)$. The prevalence of on demand breastfeeding based on the recommended practice was $129(70.9 \%)$ (Table 2$)$.

\section{Discussion}

The $2010 \mathrm{WHO}$ infant feeding guideline has recommended that HIV-infected mothers breastfeed their infants exclusively
Table I Sociodemographic characteristics of HIV positive mothers in Sidama Zone, Southern Ethiopia, 2012

\begin{tabular}{|c|c|c|}
\hline $\begin{array}{l}\text { Sociodemographic } \\
\text { characteristics }\end{array}$ & Frequency & Percentage \\
\hline \multicolumn{3}{|l|}{ Age (years), $(n=179)$} \\
\hline$\leq 24$ & 28 & 15.6 \\
\hline $25-29$ & 73 & 40.8 \\
\hline$\geq 30$ & 78 & 43.6 \\
\hline \multicolumn{3}{|l|}{ Religion $(n=184)$} \\
\hline Protestant & 101 & 54.9 \\
\hline Orthodox Christian & 64 & 34.8 \\
\hline Muslim & 15 & 8.2 \\
\hline Catholic & 4 & 2.2 \\
\hline \multicolumn{3}{|l|}{ Ethnic group $(n=184)$} \\
\hline Sidama & 62 & 33.7 \\
\hline Amhara & 37 & 20.1 \\
\hline Gurage & 30 & 16.3 \\
\hline Oromo & 28 & 15.2 \\
\hline Wolayita & 17 & 9.2 \\
\hline Other* & 10 & 5.4 \\
\hline \multicolumn{3}{|l|}{ Current marital status $(n=|8|)$} \\
\hline Married & 158 & 85.9 \\
\hline Not married/widowed & 26 & 14.1 \\
\hline \multicolumn{3}{|l|}{ Place of residence $(n=\mid 84)$} \\
\hline Urban & 134 & 72.8 \\
\hline Rural & 50 & 27.2 \\
\hline \multicolumn{3}{|l|}{ Educational status $(\mathrm{n}=179)$} \\
\hline Illiterate** & 77 & 43.0 \\
\hline Literate & 8 & 4.5 \\
\hline Primary education ( $\mathrm{I}-8$ years) & 53 & 29.6 \\
\hline Secondary education (9+ years) & 41 & 22.9 \\
\hline \multicolumn{3}{|l|}{ Sex of infant $(n=184)$} \\
\hline Male & 106 & 57.6 \\
\hline Female & 78 & 42.4 \\
\hline \multicolumn{3}{|l|}{ Monthly income (ETB), $(n=|| 6)$} \\
\hline$\leq 500$ & 67 & 57.8 \\
\hline $50 I-I, 000$ & 29 & 25.0 \\
\hline$\geq I, 001$ & 20 & 17.2 \\
\hline \multicolumn{3}{|l|}{ Birth order $(n=176)$} \\
\hline I & 54 & 30.7 \\
\hline $2-3$ & 94 & 53.4 \\
\hline$\geq 4$ & 28 & 15.9 \\
\hline \multicolumn{3}{|l|}{ Family size $(n=182)$} \\
\hline$\leq 3$ & 50 & 27.5 \\
\hline $4-5$ & 103 & 56.6 \\
\hline$\geq 6$ & 29 & 15.9 \\
\hline \multicolumn{3}{|l|}{ Age of infants $(n=184)$} \\
\hline 6-8 months & 69 & 37.5 \\
\hline 9-II months & 45 & 24.5 \\
\hline $12-17$ months & 70 & 38.0 \\
\hline
\end{tabular}

Notes: *Tigre, Kambata and Gamo; **those without any formal education. Abbreviation: ETB, Ethiopian Birr.

for the first 6 months, then introduce appropriate complementary foods and continue breastfeeding for the first 12 months. ${ }^{11}$ In the current study, about $28.9 \%$ of infants in the age category of 6-11 months were not being breastfed. This finding is consistent with a study done in Uganda which 
Table 2 Breastfeeding patterns and practices of HIV positive mothers in Sidama Zone, Southern Ethiopia, 2012

\begin{tabular}{|c|c|c|}
\hline Variable & Frequency & Percentage \\
\hline \multicolumn{3}{|l|}{ Ever breastfed } \\
\hline Yes & 181 & 98.4 \\
\hline No & 3 & 1.6 \\
\hline \multicolumn{3}{|c|}{ Breastfeeding initiated } \\
\hline Within I hour & 158 & 87.3 \\
\hline After I hour & 23 & 12.7 \\
\hline \multicolumn{3}{|l|}{ Colostrum fed } \\
\hline Yes & 157 & 85.8 \\
\hline No & 26 & 14.2 \\
\hline \multicolumn{3}{|c|}{ Prelacteal food given } \\
\hline Yes & 31 & 16.8 \\
\hline No & 153 & 83.2 \\
\hline \multicolumn{3}{|c|}{ Breastfeeding stopped } \\
\hline \multicolumn{3}{|c|}{ (for infants aged 6-II months) } \\
\hline Yes & 33 & 28.9 \\
\hline No & 81 & 71.1 \\
\hline \multicolumn{3}{|c|}{ Breastfeeding stopped before } \\
\hline \multicolumn{3}{|c|}{12 months (for infants aged } \\
\hline \multicolumn{3}{|l|}{$\geq 12$ months) } \\
\hline Yes & 22 & 66.7 \\
\hline No & 11 & 33.3 \\
\hline \multicolumn{3}{|c|}{ On demand breastfeeding } \\
\hline Yes & 129 & 70.9 \\
\hline No & 53 & 29.1 \\
\hline \multicolumn{3}{|c|}{ Scheduled breastfeeding } \\
\hline Yes & 26 & 14.3 \\
\hline No & 156 & 85.7 \\
\hline \multicolumn{3}{|c|}{ Breastfeed when child cries } \\
\hline Yes & 30 & 16.5 \\
\hline No & 152 & 83.5 \\
\hline \multicolumn{3}{|c|}{ Breastfeed on convenience } \\
\hline Yes & 11 & 6 \\
\hline No & 171 & 94.0 \\
\hline \multicolumn{3}{|c|}{$\begin{array}{l}\text { Breastfeed when the breast } \\
\text { was engorged }\end{array}$} \\
\hline Yes & 10 & 5.5 \\
\hline No & 172 & 94.5 \\
\hline
\end{tabular}

showed that $27 \%$ of infants under 12 months had stopped being breastfed. ${ }^{15}$ However, the recommendation for HIV positive mothers during the Ugandan study was different from the current one. This study also found that $47.8 \%$ of infants aged $\geq 12$ months were not being breastfed currently. The mean $( \pm \mathrm{SD})$ duration of breastfeeding among infants who had stopped being breastfed was $7.8( \pm 3.1)$ months. The Ugandan study reported that median breastfeeding duration among HIV positive mothers was 12 months. ${ }^{15}$ Recent studies indicate that for many babies in resource poor homes, stopping breastfeeding carries a higher risk of death (from infection and malnutrition) than continued breastfeeding. ${ }^{16,17}$ The breastfeeding practice of HIV positive mothers was not consistent with the current recommendations of WHO regarding breastfeeding. One of the possible reasons for this high prevalence of inappropriate breastfeeding pattern and practices among HIV-exposed infants could be the implementation of the previous WHO guidelines which recommend total avoidance of breastfeeding if the "acceptable, feasible, affordable, sustainable and safe" (AFASS) criterion is fulfilled. A study from four African countries showed that health workers were found to significantly overestimate the risk of HIV transmission through breastfeeding while the risks of non-breastfeeding were rarely communicated to mothers even though reports of high mortality have been reported among infants who were formula fed. ${ }^{18}$ So there is a need for continuous follow-up of the health facilities by respective health program administrators and program evaluators to avoid such inconsistent/inappropriate implementation of the recommendations to avert HIV transmission and making the zero transmission a realistic goal for PMTCT intervention and to adopt the new WHO recommendation to safeguard the health of children.

The prevalence of continued breastfeeding was $46.9 \%$ among urban and $75 \%$ among rural mothers. But there is no significant difference in the prevalence of continued breastfeeding by place of residence. It is consistent with the global prevalence of continued partial breastfeeding at 1 year which remains relatively high ( $76 \%) .{ }^{19} \mathrm{In}$ fact, this study has a small number of study subjects which might not reflect the prevalence of the actual practice. Prolonged breastfeeding increases the risk for mother to child transmission of the virus. According to $2010 \mathrm{WHO}$ guidelines breastfeeding should only be stopped once a nutritionally adequate and safe diet without breast milk can be provided and should then be stopped gradually within 1 month.

The prevalence of timely initiation of breastfeeding $(87.3 \%)$ was lower as compared to the findings reported from Tanzania (95.4\%) and South Africa (96\%). ${ }^{20,21}$ Another South African study reported that almost a third of HIV positive women initiated breastfeeding within 1 hour of giving birth. ${ }^{22}$ Delayed breastfeeding initiation has been reported to increase the risk of neonatal death. ${ }^{23}$ Encouraging earlier breastfeeding initiation could thus increase infant survival.

The prevalence of colostrum feeding in the current study $(85.8 \%)$ is comparable with the study from South Africa which reported that most mothers (85\%) offered colostrum to their babies while $13 \%$ of mothers threw it away. ${ }^{21}$ This study found low prevalence of prelacteal feeding (16.8\%) as compared to a study from Uganda (64\%) and South Africa (37\%) among HIV positive women. ${ }^{15,22}$ This might have resulted from the fact that those mothers 
received information promoting colostrum feeding during antenatal visits and delivery services along with other necessary counseling sessions to encourage the pregnant and lactating women.

Despite the fact that on demand breastfeeding is recommended practice according to the Ethiopian IYCF guidelines, only $70.9 \%$ of mothers practiced on demand breastfeeding. It is a little higher as compared to a study done in South Eastern Ethiopia, which reported $63.3 \%{ }^{24}$ The difference can be explained by the fact that those HIV positive mothers have monthly follow-up visits at the health institutions even after they have given birth and may be receiving more counseling about on demand breastfeeding.

This study has its own limitations including the small sample size, recall bias since the breastfeeding practice happened in the past, and selection bias as the study population was HIV positive mothers who attended health facilities/clinics.

\section{Conclusion}

The breastfeeding practice of HIV positive mothers was suboptimal when it was evaluated according to the updated Ethiopian and WHO recommendations regarding HIV and infant feeding. Promotion of and counseling regarding optimal breastfeeding for HIV positive mothers using the updated national and international recommendations is an appropriate intervention. However, further research is recommended to evaluate the acceptance of the 2010 WHO guidelines on HIV and infant feeding by the health professionals and HIV positive mothers.

\section{Acknowledgments}

We are highly grateful to the Higher Education Network for Applied Human Nutrition between Eastern Africa and Europe (HENNA) project and the African, Caribbean, and Pacific (ACP)/Edulink programme for financing this study. The funders did not have any role in the study design, data collection, analysis, decision to publish or preparation of the manuscript.

\section{Author contributions}

$\mathrm{DH}$ conceived and designed the study and drafted the manuscript. TS assisted in designing the study, result interpretation, and reviewed the manuscript critically. SB assisted in data interpretation and reviewed the manuscript critically. All authors contributed toward data analysis, drafting and critically revising the paper, gave final approval of the version to be published, and agree to be accountable for all aspects of the work.

\section{Disclosure}

The authors have no conflict of interest to disclose.

\section{References}

1. Breastfeeding and HIV International Transmission Study Group. Late postnatal transmission of HIV-1 in breast-fed children: an individual patient data meta-analysis. J Infect Dis. 2004;189(12):2154-2166.

2. Coovadia H, Rollins N, Bland R, et al. Mother-to-child transmission of HIV-1 infection during exclusive breastfeeding in the first 6 months of life: an intervention cohort study. Lancet. 2007;369(9567):1107-1116.

3. WHO/UNICEF/UNFPA/UNAIDS. HIV Transmission Through Breastfeeding, a Review of Available Evidence 2007 Update. Geneva: World Health Organization; 2008. Available from: http://whqlibdoc.who.int/ publications/2008/9789241596596_eng.pdf. Accessed May 4, 2015.

4. WHO/UNICEF/UNFPA/UNAIDS. New Data on the Prevention of Mother-to-Child Transmission of HIV and Their Policy Implications. Geneva: World Health Organization; 2001. Available from: http:// whqlibdoc.who.int/hq/2001/WHO_RHR_01.28.pdf. Accessed May 4, 2015.

5. World Health Organization. WHO HIV and Infant Feeding Technical Consultation Held on behalf of the Inter-agency Task Team (IATT) on Prevention of HIV Infections in Pregnant Women, Mothers and their Infants. Geneva: World Health Organization; 2006. Available from: http://www.who.int/maternal_child_adolescent/documents/pdfs/ who_hiv_infant_feeding_technical_consultation.pdf. Accessed May 4, 2015.

6. Arpadi S, Fawzy A, Aldrovandi G, et al. Growth faltering due to breastfeeding cessation in uninfected children born to HIV-infected mothers in Zambia. Am J Clin Nutr. 2009;90(2):344-353.

7. Kafulafula G, Hoover D, Taha T, et al. Frequency of gastroenteritis and gastroenteritis-associated mortality with early weaning in HIV-1uninfected children born to HIV-infected women in Malawi. J Acquir Immune Defic Syndr. 2010;53(1):6-13.

8. Onyango-Makumbi C, Bagenda D, Mwatha A, et al. Early weaning of HIV-exposed uninfected infants and risk of serious gastroenteritis: findings from two perinatal HIV prevention trials in Kampala, Uganda. J Acquir Immune Defic Syndr. 2010;53(1):20-27.

9. Kesho Bora Study Group. Eighteen-month follow-up of HIV-1-infected mothers and their children enrolled in the Kesho Bora study observational cohorts. Acquir Immune Defic Syndr. 2010;54(5):533-541.

10. Kesho Bora Study Group, de Vincenzi I. Triple antiretroviral compared with zidovudine and single-dose nevirapine prophylaxis during pregnancy and breastfeeding for prevention of mother-to-child transmission of HIV-1 (Kesho Bora study): a randomised controlled trial. Lancet Infect Dis. 2011;11(3):171-180.

11. WHO/UNAIDS/UNFPA/UNICEF. Guidelines on HIV and Infant Feeding: Principles and Recommendations for Infant Feeding in the Context of HIV and a Summary of Evidence. Geneva: World Health Organization; 2010. Available from: http://whqlibdoc.who.int/publications/2010/9789241599535_eng.pdf. Accessed May 4, 2015.

12. Filteau S. The HIV-exposed, uninfected African child. Trop Med Int Health. 2009;14(3):276-287.

13. Federal Ministry of Health Ethiopia. Guidelines for Prevention of Mother-to-Child Transmission of HIV in Ethiopia. Federal Ministry of Health Ethiopia. Available from: http://www.ilo.org/wcmsp5/groups/ public/---ed_protect/---protrav/---ilo_aids/documents/legaldocument/ wcms_125389.pdf. Accessed May 4, 2015.

14. World Health Organization [homepage on the Internet]. Indicators for assessing infant and young child feeding practices; 2008. World Health Organization. Available from: http://www.who.int/maternal_child_ adolescent/documents/9789241596664/en/. Accessed May 4, 2015.

15. Fadnes LT, Engebretsen IM, Wamani H, et al. Infant feeding among HIV-positive mothers and the general population mothers: comparison of two cross-sectional surveys in Eastern Uganda. BMC Public Health. 2009;9:124. 
16. Kuhn L, Aldrovandi G, Sinkala M, et al. Differential effects of early weaning for HIV-free survival of children born to HIV-infected mothers by severity of maternal disease. PLoS One. 2009;4(6):e6059.

17. Taha TE, Hoover DR, Chen S, et al. Effects of Cessation of Breastfeeding in HIV-1-Exposed, Uninfected Children in Malawi. Clin Infect Dis. 2011;53(4):390-393.

18. Chopra M, Rollins N. Infant feeding in the time of HIV: rapid assessment of infant feeding policy and programmes in four African countries scaling up prevention of mother to child transmission programmes. Arch Dis Child. 2008;93(4):288-291.

19. UNICEF. Progress for Children: A world fit for children statistical review. New York: UNICEF; 2007. Available from: http://www. childinfo.org/files/education_progress_for_children.pdf. Accessed February 9, 2015.

20. Young SL, Israel-Ballard KA, Dantzer EA, et al. Infant feeding practices among HIV-positive women in Dar es Salaam, Tanzania, indicate a need for more intensive infant feeding counselling. Public Health Nutr. 2010;13(12):2027-2033.
21. Ghuman M, Saloojee H, Morris G. Infant feeding practices in a high HIV prevalence rural district of KwaZulu-Natal, South Africa. South African Journal of Clinical Nutrition. 2009;22(2):74-77.

22. Doherty T, Sanders D, Jackson D, et al. Early cessation of breastfeeding amongst women in South Africa: an area needing urgent attention to improve child health. BMC Pediatr. 2012;12:105.

23. Edmond K, Zandoh C, Quigley M, et al. Delayed breastfeeding initiation increases risk of neonatal mortality. Pediatrics. 2006;117(3): e380-e386.

24. Setegn T, Belachew T, Gerbaba M, et al. Factors associated with exclusive breastfeeding practices among mothers in Goba district, south east Ethiopia: a cross-sectional study. International Breastfeeding Journal. 2012;7:17.

\section{Publish your work in this journal}

Pediatric Health, Medicine and Therapeutics is an international, peerreviewed, open access journal publishing original research, reports, editorials, reviews and commentaries. All aspects of health maintenance, preventative measures and disease treatment interventions are addressed within the journal. Practitioners from all disciplines are invited to submit their work as well as healthcare researchers and patient support groups. The manuscript management system is completely online and includes a very quick and fair peer-review system. Visit http://www.dovepress.com/ testimonials.php to read real quotes from published authors.

Submit your manuscript here: http://www.dovepress.com/pediatric-health-medicine-and-therapeutics-journal 